\title{
Emergência e Matéria Seca de Plantas Daninhas na Cultura do MAMOEIRO (Carica papaya) ${ }^{1}$
}

\author{
Emergence and Dry Matter of Weeds in Papaya Crop (Carica Papaya)
}

\author{
SANTANA, I.S. ${ }^{2}$, PEIXOTO, M.F.S.P. ${ }^{3}$, CARVALHO, J.E.B. ${ }^{4}$, SAMPAIO, L.S.V. ${ }^{5}$, LEDO, C.A.S. ${ }^{4}$ e \\ PEIXOTO, C.P. ${ }^{5}$
}

\begin{abstract}
RESUMO - O objetivo deste experimento foi avaliar o "banco" de sementes de plantas daninhas através do método da emergência de plântulas, na cultura do mamoeiro, em que se empregaram diferentes sistemas de manejo. O delineamento experimental foi em blocos casualizados, com três repetições e seis tratamentos: capina em área total; herbicida nas linhas + grade nas entrelinhas; subsolagem cruzada antes do plantio + capina em área total; subsolagem cruzada antes do plantio + herbicida nas linhas e feijão de porco nas entrelinhas; subsolagem cruzada antes do plantio + herbicida nas linhas e crotalária nas entrelinhas; e herbicida nas linhas + vegetação nativa nas entrelinhas da cultura, roçada quando necessário. A avaliação do banco de sementes foi feita aos 30, 60, 90 e 120 dias após a implantação de um bioensaio em casa de vegetação, com amostras retiradas no campo nas épocas chuvosa e seca, na profundidade de $0-15 \mathrm{~cm}$. A matéria seca das plantas daninhas foi obtida utilizando-se um quadrado de $0,5 \times 0,5 \mathrm{~m}$, jogado a lanço quatro vezes nas parcelas. Os sistemas de manejo de capina em área total e de herbicida na linha + grade nas entrelinhas de plantio de mamoeiros, com feijão-de-porco e crotalária, reduzem o banco de sementes no solo. Dos adubos verdes, crotalária e feijão-de-porco, o primeiro altera a dinâmica do "banco" de sementes de forma mais significativa.
\end{abstract}

Palavras-chave: banco de sementes, manejo de solo.

\begin{abstract}
The objective of this work was to evaluate the seed bank of weeds through the seedling emergence method in papay a crop, using different tillage systems. A randomized complete block design was used, with three replications and six treatments: weeding in total area, herbicide in the rows + disc in the interrows, crossed sub soiling before planting + weeding in total area, crossed sub soiling before planting + herbicide in the rows and pig bean in the interrows, crossed sub soiling before planting + herbicide in the row + crotalaria in the interrows and crossed sub soiling before planting + herbicide in the rows + native vegetation in the interrows, cleared when necessary. Seed bank evaluation was performed at 30, 60, 90 and 120 days after implantation of the experiment in the greenhouse with samples collected in the field in the rainy and dry seasons at $0-15 \mathrm{~cm}$ in depth. Weed dry matter was obtained by using a square of $0.5 \times 0.5 \mathrm{~m}$ sorted four times in the plots. The weeding management systems in total area and herbicide in the row + disc in the papaya crop interrows with pig bean and crotalaria reduce seed bank in the soil. Among the green fertilizers, crotalaria alters more significantly the dynamics of the seed bank than pig bean.
\end{abstract}

Key words: seed bank, soil management.

1 Recebido para publicação em 16/6/2004 e na forma revisada em 25/11/2005.

Parte da dissertação do primeiro autor.

2 Mestre em Agronomia, Departamento de Química Agrícola e Solos, Escola de Agronomia da Universidade Federal da Bahia UFBA, 44380-000 Cruz das Almas-BA, <izafrance@yahoo.com.br>; ${ }^{3}$ Professor Adjunto, Departamento de Química Agrícola e Solos, Escola de Agronomia da UFBA. ${ }^{4}$ Pesquisador D.S. do Centro Nacional de Pesquisa de Mandioca e Fruticultura (CNPMF/ EMBRAPA), 44.380.000 Cruz das Almas-BA. ${ }^{5}$ Professor Adjunto, Departamento de Fitotecnia, Escola de Agronomia da UFBA. 


\section{INTRODUÇÃO}

O banco ou reserva de sementes é uma agregação de sementes não-germinadas, mas potencialmente capazes de substituir plantas adultas anuais que desaparecem por causa natural ou não, ou perenes, suscetiveis a doenças, distúrbios ou consumo por animais (Baker, 1989). Esse termo tem sido adotado para designar as reservas de sementes viáveis no solo, em profundidade e na superfície (Roberts, 1981).

O conhecimento de bancos de sementes de plantas daninhas permite construir modelos de estabelecimentos populacionais ao longo do tempo, possibilitando a definição de programas estratégicos de controle. Dessa forma, o conhecimento da taxa de emergência dessas espécies pode servir para adequar manejos de solo e da cultura, que devem resultar na racionalização do uso de herbicidas (Martins \& Silva, 1994; Voll et al., 1996).

Podem-se usar diferentes técnicas para a avaliação do tamanho e da composição do banco de sementes, como a observação in loco da emergência de plântulas. Este método, no entanto, não é preciso, pois as sementes podem permanecer viáveis no solo por um longo período sem germinar, e algumas sementes germinadas não chegam a emergir devido às condições ambientais desfavoráveis ou profundidade de enterrio excessiva (Mortimer, 1990). Atualmente, utiliza-se determinar o número de sementes viáveis colocando-se amostra de solo em local apropriado, geralmente casa de vegetação, permitindo-se que as sementes germinem (Roberts, 1981).

Diferentes sistemas de manejo do solo condicionam as sementes a microambientes, devido às alterações das propriedades físicoquímicas e nas condições da superfície do solo (Mulugueta \& Stoltemberg, 1997). Sistemas de manejo que causam menos distúrbio favorecem um maior e mais diversificado banco de sementes (Feldman et al., 1997). A intensidade de emergência depende do tamanho do banco de sementes e o aumento de cultivo de solo promove maior emergência de plântulas daninhas. Os resultados encontrados das taxas de emergência anual de carrapicho foram menores no sistema de manejo de semeadura direta; maiores no convencional e no de aivecas; e intermediários no de escarificação e grade rome. As sementes situadas na camada superficial, submetidas às maiores variações de temperatura e umidade, tendem a ter sua dormência superada e a germinar e emergir em maior intensidade, porém reduzindo seu período de sobrevivência (Voll et al., 1997).

Guando se utiliza a roçadeira, ocorre o corte da vegetação, sendo esta mantida na superfície do solo. Se a vegetação apresentar sementes, estas podem germinar ou permanecer dormentes. Como na gradagem, a profundidade de corte é considerada pequena (menos que $10 \mathrm{~cm}$ ), conseqüentemente maior número de sementes também permanece na superfície do solo. A emergência dessas sementes vai depender da época e da intensidade dos cultivos do solo, da distribuição das sementes no perfil, da cobertura dos restos vegetais e das condições de dormência das sementes (Yenish et al., 1992).

A não-movimentação do solo e a cobertura vegetal, em semeadura direta, resultam em menor emergência das sementes no solo. De acordo com a espécie e quantidade dessa cobertura, substâncias alelopáticas e sombreamento determinam variações nas intensidades de emergência das espécies daninhas (Teasdale et al., 1991).

Estudando-se a dinâmica do banco de sementes de plantas daninhas na cultura do citro, verificou-se que a grande massa vegetal formada pelas leguminosas guandu (Cajanus cajan) e lab-lab (Dolichus lablab) inibiu a germinação das sementes das plantas daninhas e o estabelecimento de plântulas, provavelmente por competição por luz ou efeito alelopático (Caetano, 2000).

Em trabalho para avaliar o efeito de leguminosas quanto à capacidade de inibir o desenvolvimento de plantas daninhas, em solos de Tabuleiros Costeiros, constatou-se que as leguminosas de folha larga e crescimento rápido, mucuna-preta e feijão-de-porco, foram as mais eficientes e que Crotalaria spectabilis foi muito superior a Crotalaria breviflora, provavelmente por efeito alelopático (Fernandes et al., 1998). 
O controle químico de plantas daninhas com o uso dos herbicidas favorece o declínio no banco de sementes após aplicações repetidas (Schweizer $\&$ Zimdahl, 1984). Doses reduzidas de herbicidas diminuem a produção de sementes de diversas espécies de plantas daninhas em mais de $90 \%$. No entanto, o número de sementes pode aumentar rapidamente quando o uso do herbicida é descontínuo e intercalado com outras práticas de manejo (Salzman et al., 1988).

Este trabalho teve como objetivo avaliar o "banco" de sementes de plantas daninhas, através do método de emergência de plântulas, na cultura do mamoeiro em que se empregaram diferentes sistemas de manejo.

\section{MATERIAL E MÉTODOS}

O experimento foi implantado no Campo Experimental II da Escola de Agronomia da Universidade Federal da Bahia, localizado no município de Cruz das Almas, Bahia, situado no Recôncavo Baiano. O solo da área experimental é classificado como Latossolo Amarelo coeso, "A" moderado, textura franco-argilo-arenosa e relevo plano (Rezende, 2000), possuindo os seguintes atributos químicos: $\mathrm{pH} \mathrm{CaCl}=$ 5,$2 ; \mathrm{M} . \mathrm{O}=20,26 \mathrm{~g} \mathrm{dm}^{-3} ; \mathrm{P}=10,0 \mathrm{mg} \mathrm{dm}^{-3} ; \mathrm{K}=$ $0,21 \mathrm{cmol}_{\mathrm{c}} \mathrm{dm}^{-3} ; \mathrm{Ca}=1,6 \mathrm{cmol}_{\mathrm{c}} \mathrm{dm}^{-3} ; \mathrm{Mg}=$ $0,66 \mathrm{cmol}_{\mathrm{c}} \mathrm{dm}^{-3} ; \mathrm{Al}^{+3}=21 \mathrm{cmol}_{\mathrm{c}} \mathrm{dm}^{-3} ; \mathrm{H}+\mathrm{Al}=$ $2,09 \mathrm{cmol}_{\mathrm{c}} \mathrm{dm}^{-3} ; \mathrm{S}=2,47 \mathrm{cmol}_{\mathrm{c}} \mathrm{dm}^{-3}$; e $\mathrm{V}=$ $54,16 \%$. Os tratamentos utilizados foram: sistema do pequeno produtor - capina em área total (CAT); sistema do médio produtor herbicida nas linhas e grade nas entrelinhas da cultura (HLGE); sistema do pequeno produtor - subsolagem cruzada antes do plantio + capina em área total (SCAT); subsolagem cruzada antes do plantio + herbicida nas linhas e feijão-de-porco (Canavalia ensiformis) nas entrelinhas da cultura (SHFP); subsolagem cruzada antes do plantio + herbicida nas linhas e Crotalaria juncea nas entrelinhas da cultura (SHC); e subsolagem cruzada antes do plantio + herbicida nas linhas e vegetação nativa nas entrelinhas da cultura, roçada quando necessário (SHR). A área total de cada parcela foi de $216 \mathrm{~m}^{2}$, sendo composta por 36 plantas, das quais 16 foram consideradas úteis. O espaçamento utilizado foi de $3,0 \mathrm{~m}$ entre linhas e 2,0 $\mathrm{m}$ entre plantas.
A subsolagem foi realizada na área experimental de forma cruzada, numa profundidade média de $55 \mathrm{~cm}$, antes da implantação do experimento, utilizando-se um subsolador com duas hastes espaçadas de $1,50 \mathrm{~m}$. As leguminosas foram semeadas em plantio direto, após dessecação da vegetação existente nas entrelinhas do mamão com glifosato a 1\% $\mathrm{v} / \mathrm{v}$, no equivalente a $80 \mathrm{~kg} \mathrm{ha}^{-1}$ no caso do feijão-de-porco (três a cinco sementes por metro linear) e $24 \mathrm{~kg} \mathrm{ha}^{-1}$ para crotalária (25 sementes por metro linear). Utilizou-se o espaçamento entre linhas de 0,35/0,40 para cobrir mais rapidamente o solo. As plantas infestantes foram controladas em área total com capinas mecânicas nos tratamentos CAT e SCAT. Nas entrelinhas dos tratamentos HLGE e SHR o controle mecânico foi feito com grade e com roçadeira, respectivamente. Nos tratamentos em que se empregou o glifosato a dosagem aplicada foi de $1 \% \mathrm{v} / \mathrm{v}$, utilizando-se pulverizador costal a uma vazão média de $250 \mathrm{~L} \mathrm{ha}^{-1}$, com bico em leque 110.02 (amarelo).

A emergência das plântulas foi avaliada em duas épocas do ano: seca (dezembro de 2002) e chuvosa (julho de 2003), retirando-se 10 subamostras de $1 \mathrm{~kg}$, em caminhamento em ziguezague a uma profundidade de 0 a $15 \mathrm{~cm}$ em todas as parcelas experimentais. De cada amostra composta de $10 \mathrm{~kg}$ de solo, retiraram-se três subamostras, de $1 \mathrm{~kg}$ cada, que foram colocadas em bandejas de plástico com dimensões de $29 \times 19 \times 4 \mathrm{~cm}$. O bioensaio foi instalado em casa de vegetação da Embrapa Mandioca e Fruticultura, adotando-se o delineamento experimental de blocos casualizados (DBC), com seis tratamentos e três repetições (para cada tratamento utilizaram-se três bandejas para linha e três bandejas para entrelinha). Aos 30, 60, 90 e 120 dias após a instalação do experimento, realizou-se a contagem das plântulas emergidas (adaptado de Caetano, 2000).

A avaliação da matéria seca das plantas daninhas por área $\left(\mathrm{m}^{2}\right)$ foi feita no mesmo período da coleta de amostras para o estudo de emergência, de acordo com a metodologia descrita por Carvalho (2003).

Os resultados foram analisados utilizandose o programa estatístico SAS - Statistical Analysis System (SAS Institute Inc., 2000), e

Planta Daninha, Viçosa-MG, v. 23, n. 4, p. 583-588, 2005 
as médias dos tratamentos, submetidas ao teste de Scott e Knott (1974) a 5\% de probabilidade.

\section{RESULTADOS E DISCUSSÃO}

\section{Intensidade de plântulas emergidas das espécies daninhas}

Na época seca, na linha, os tratamentos que propiciaram maior número de plântulas emergidas foram HLGE, SCAT e SHFP, diferindo dos demais tratamentos, sem, contudo, diferir significativamente entre si pelo teste de Scott-Knott a 5\%. Na época chuvosa, na linha, observa-se que os tratamentos HLGE, SCAT, SHFP e SHR pertenciam a um mesmo grupo, apresentando maior número de plântulas emergidas (Figura 1).

Com relação às amostras retiradas das entrelinhas na época seca, verifica-se que os tratamentos HLGE, SCAT e SHFP propiciaram a maior emergência, porém pertencem ao mesmo grupo pelo teste de Scott-Knott a 5\%. $\mathrm{Na}$ época chuvosa, na entrelinha, os tratamentos HLGE e SCAT pertencem ao mesmo grupo pelo teste de Scott e Knott, ocorrendo diferença significativa em relação aos demais tratamentos.

Observa-se também na Figura 1 que, de maneira geral, tanto na época seca quanto na chuvosa, os tratamentos que apresentaram menor número de plântulas daninhas emergidas foram CAT e $\mathrm{SHC}$, e o maior número, HLGE e SCAT. Evidencia-se também, quando se comparam os tratamentos capina, com e sem subsolagem (SCAT e CAT), que a prática da subsolagem contribuiu para o aumento do número de plântulas emergidas.

Existe uma relação direta entre o aumento do cultivo do solo e a emergência de plântulas daninhas. Sementes situadas na camada superficial, submetidas às maiores variações de temperatura e umidade, tendem a ter sua dormência superada e a germinar e emergir
LINHA - ÉPOCA SECA

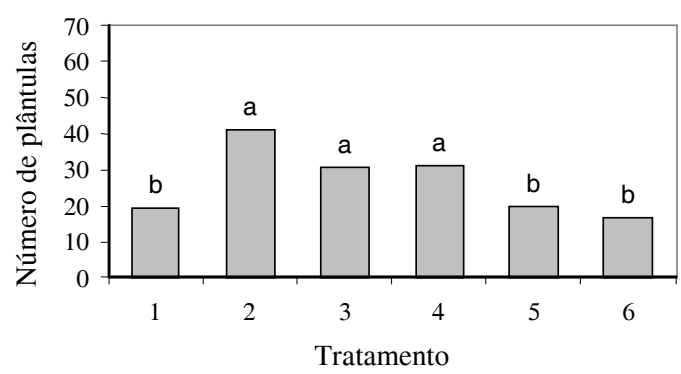

LINHA - ÉPOCA CHUVOSA

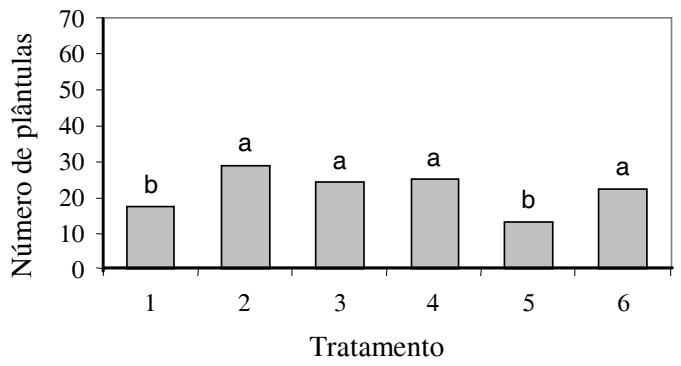

ENTRELINHA - ÉPOCA SECA

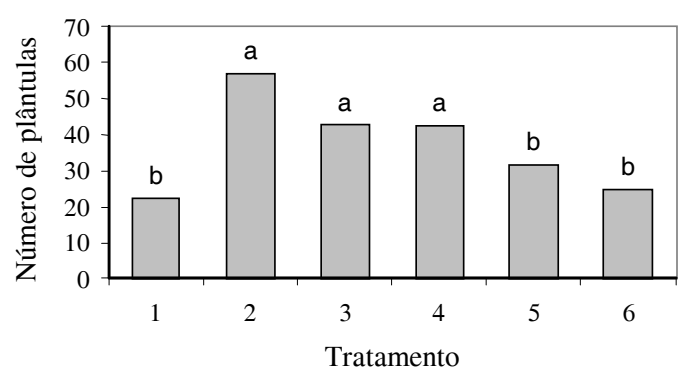

ENTRELINHA - ÉPOCA CHUVOSA

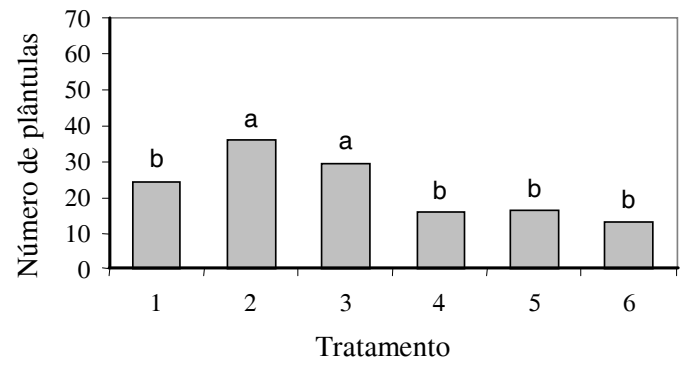

Médias seguidas pela mesma letra pertencem ao mesmo grupo pelo teste de Scott-Knott a 5\% de probabilidade.

Figura 1 - Número de plântulas emergidas nas linhas e nas entrelinhas na avaliação das amostras coletadas nos tratamentos em duas épocas do ano (época seca e época chuvosa). Tratamentos: 1 - capina em área total (CAT); 2 - herbicida nas linhas e grade nas entrelinhas (HLGE); 3 - capina em área total e subsolagem cruzada antes do plantio (SCAT); 4 - herbicida nas linhas e feijão-deporco nas entrelinhas (SHFP); 5 - herbicida nas linhas e crotalária nas entrelinhas (SHC); e 6 - herbicida nas linhas e roçadeira nas entrelinhas (SHR). 
(Voll et al., 1997). A prática da gradagem propicia a movimentação do solo, transportando as sementes das camadas mais profundas e as expondo na superfície, sendo a germinação dependente, entre outros fatores, do estado de dormência das sementes.

Em ambas as épocas, tanto na linha quanto na entrelinha, a capina em área total com subsolagem (SCAT) apresentou-se menos eficiente na redução da população de sementes de plantas daninhas no solo, em comparação com o tratamento em que se utilizou a leguminosa crotalária combinada com herbicida e subsolagem (SHC). A combinação SCAT e HLGE teve o mesmo efeito sobre o banco de sementes nas duas épocas (seca e chuvosa) e locais amostrados (linha e entrelinha).

Nos sistemas de manejo em que foram usadas as leguminosas feijão-de-porco (SHFP) e crotalária (SHC), combinadas com subsolagem e herbicida (Figura 1), observa-se, de maneira geral, comportamento diferenciado, com o feijão-de-porco contribuindo menos significativamente para a redução do estoque de sementes no solo. Esses resultados concordam com os de Fernandes et al. (1998) e Caetano (2000). Apesar de ambas as espécies serem leguminosas, há uma diferença de arquitetura destas. A crotalária caracterizase por deixar o solo parcialmente coberto, permitindo a entrada de mais luz, propiciando condição mais favorável à germinação das sementes. De acordo com Tesdale et al. (1991), sombreamento e substâncias alelopáticas determinam variações nas intensidades de emergência das espécies daninhas. Fernandes et al. (1998) identificaram substâncias alelopáticas em duas espécies de crotalária, associadas ao controle de plantas daninhas.

Houve efeito da roçagem quando combinada com herbicida e subsolagem (SHR) na diminuição do estoque do banco de sementes nas épocas seca e chuvosa, na entrelinha, e na época seca, na linha (Figura 1). Segundo Yenish et al. (1992), quando se utiliza roçadeira ocorre o corte da vegetação, sendo esta mantida na superfície do solo. Se a vegetação apresentar sementes, estas podem germinar ou permanecer dormentes.

De maneira geral, houve diminuição do estoque de sementes no solo quando se utilizou o herbicida glifosato combinado com subsolagem e crotalária (SHC), bem como glifosato combinado com subsolagem e roçagem (SHR), na linha e entrelinha, nas épocas seca e chuvosa (Figura 1).

\section{Matéria seca de plantas daninhas}

Na época seca, observa-se que os tratamentos CAT, HLGE e SCAT pertencem ao mesmo grupo pelo teste de Scott e Knott a 5\%. Os tratamentos SHFP, SHC e SHR também pertencem ao mesmo grupo, ocorrendo, portanto, diferença entre estes e os demais tratamentos do outro grupo. Na época chuvosa, todos os tratamentos pertencem ao mesmo grupo, não havendo influência dos sistemas de manejo adotados no controle de plantas daninhas (Figura 2).
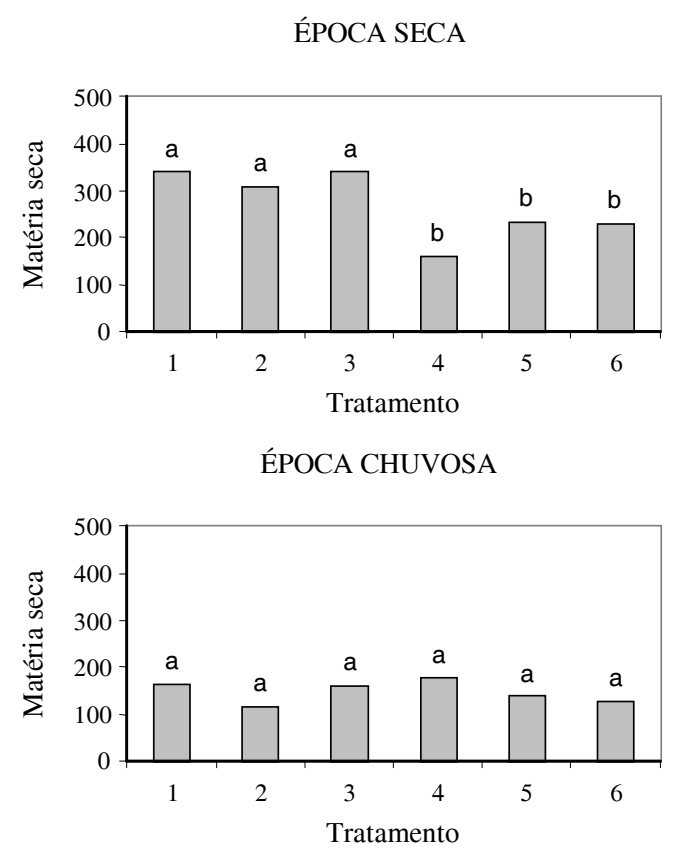

Médias seguidas pela mesma letra pertencem ao mesmo grupo pelo teste de Scott-Knott a $5 \%$ de probabilidade.

Figura 2 - Matéria seca das plantas emergidas na avaliação das amostras coletadas nos tratamentos nas épocas seca (dezembro de 2002) e chuvosa (julho de 2003). Tratamentos: 1 - capina em área total (CAT); 2 - herbicida nas linhas e grade nas entrelinhas (HLGE); 3 - capina em área total e subsolagem cruzada antes do plantio (SCAT); 4 - subsolagem cruzada antes do plantio, herbicida nas linhas e feijão-deporco nas entrelinhas (SHFP); 5 - subsolagem cruzada antes do plantio, herbicida nas linhas e crotalária nas entrelinhas (SHC); e 6 - subsolagem cruzada antes do plantio, herbicida nas linhas e roçadeira nas entrelinhas (SHR).

Planta Daninha, Viçosa-MG, v. 23, n. 4, p. 583-588, 2005 
Comparando os acúmulos de matéria seca das plantas daninhas, encontradas no campo, na época seca (Figura 2) com o número de plântulas emergidas nas linhas e entrelinhas nesta mesma época, resultante da avaliação da reserva de sementes viáveis no solo (Figura 1), nota-se uma relação direta entre essas variáveis nos tratamentos HLGE e SCAT, confirmando que sistemas de manejo que propiciam maior distúrbio no solo contribuem para aumentar o número de sementes nas camadas mais próximas à superfície, facilitando sua germinação.

Evidencia-se também, na época seca, que os sistemas de manejo que propiciam a permanência de cobertura vegetal (SHFP, SHC e SHR) diminuem a infestação de plantas daninhas (Figura 2).

No período estudado e nas condições do experimento, conclui-se que: os sistemas de manejo de capina em área total e de herbicida na linha, utilizando cobertura de leguminosas, como feijão-de-porco e crotalária, nas entrelinhas de plantios de mamoeiros, reduzem o banco de sementes no solo; e, dos adubos verdes crotalária e feijão-de-porco, o primeiro reduz (?) o "banco" de sementes de forma mais significativa.

\section{LITERATURA CITADA}

BAKER, H. G. Some aspects of natural history of seed banks. In: LECK, M. A.; PARKER, V. T.; SIMPSON, R. L. (Eds.) Ecology of soil seed banks. London, Academic Press, 1989. p. 5-19.

CAETANO, R. S. Dinâmica do banco de sementes de plantas daninhas na cultura dos citros (Citrus sinensis (L.) Osbeck) submetida a diferentes sistemas de manejo. 2000. 105 f. Tese (Doutorado em Fitotecnia) - Universidade de São Paulo, Piracicaba, 2000.

CARVALHO, J. E. B. et al. Efeito de períodos de controle de plantas daninhas sobre a produtividade de citros em São Paulo. Cruz das Almas: EMBRAPACNPMF, 2003. 4 p. (EMBRAPA-CNPMF - Comunicado Técnico, 86)

FELDMAN, S. R.et al. The effect of different tillage system on the composition of the seedbank. Weed Res., v. 37, n. 2, p. 71-76, 1997.
FERNANDES, M. F.; BARRETO, A. C.; EMÍDIO FILHO, J. Densidade de semeadura a lanço de sete leguminosas utilizadas como adubo verde em solos de tabuleiros costeiros. Aracaju: EMBRAPA-CPATC, 1998. 8 p. (EMBRAPA-CPATC - Comunicado Técnico, 18)

MARTINS, C. C.; SILVA,W. R. Estudos de banco de sementes do solo. Inf. Abrates, v. 4, p. 49-56, 1994.

MORTIMER, A. M. The biology of weed. In: HANCE, R. J.; HOLL, Y. K. (Eds.) Weed control handbook: principles. London: Blackwell Scientific Publications, 1990. p. 1-42.

MULUGUETA, D.; STOLTEMBERG, D. E. Increase weed emergence and seed bank depletion by soil disturbance in no-tillage systems. Weed Sci., v. 45, p. 234-241, 1997.

REZENDE, J. O. Solos coesos dos tabuleiros costeiros: limitações agrícolas e manejo. Salvador: SEAGRl-SPA, 2000. 117 p. (Série estudos agrícolas).

ROBERTS, H. A. Seed banks in the soil. App. Biol., v. 6, p. $1-55,1981$.

SALZAM, F. P.; SMITH, R. J.; TALBERT, R. E. Suppression of red rice (Oryza saliva) seed production. Weed Sci., v. 32, p. 76-83, 1988.

SAS INSTITUTE INC. SAS/STAT User's Guide, v. 8.0. Vol. I. Cary: 2000.

SCHWE1ZER, E. E.; ZIMDAHL, R. Li. Weed seed decline in irrigaled soil aftcr six years of continuous corn (Zea mays) and herbicides. Weed Sci., v. 32, p. 76-83, 1984.

SCOTT, A. J.; KNOTT, M. A. A cluster analysis method for grouping means in the analysis of variance. Biometrics, v. 30, n. 3, p. 507-512, 1974.

TEASDALE, J. R.; BESTE, C. E.; POTTS, W. E. Response of weeds to tillage and cover crop residue. Weed Sci., v. 39, p. 195-199, 1991.

VOLL, E.; GAZZIERO, D. L. P.; KARAM, D. Dinâmica de populações de carrapicho-de-carneiro (Acanthospermum hipidum dc) sob manejos de solo e herbicidas. Pesq. Agropec. Bras., v. 32, n. 9, p. 897-904, 1997.

VOLL, E.; GAZZIERO, D. L. P.; KARAM, D. Dinâmica de populações de Brachiaria plantaginea (Link) HITCH sob manejo de solo e de herbicidas. 2. Emergência. Pesq. Agropec. Bras., v. 30, p. 27-35, 1996.

YENISH, J. P.; DOLL, J. D.; BUHLER, D. D. Effects of tillage on vertical distribution and viabilily of weed seed in soil. Weed Sci., v. 40, p. 429-433, 1992. 